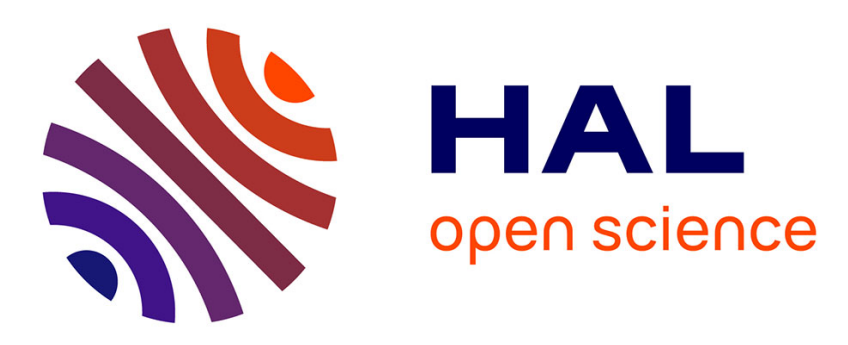

\title{
Effet de la nature de l'amidon de l'aliment concentré et de la supplémentation en méthionine sur la production et la composition du lait
}

\author{
S Jurjanz, O Colin-Schoellen, François Laurent
}

\section{- To cite this version:}

S Jurjanz, O Colin-Schoellen, François Laurent. Effet de la nature de l'amidon de l'aliment concentré et de la supplémentation en méthionine sur la production et la composition du lait. Annales de zootechnie, 1995, 44 (Suppl1), pp.379-379. hal-00889533

\section{HAL Id: hal-00889533 \\ https://hal.science/hal-00889533}

Submitted on 1 Jan 1995

HAL is a multi-disciplinary open access archive for the deposit and dissemination of scientific research documents, whether they are published or not. The documents may come from teaching and research institutions in France or abroad, or from public or private research centers.
L'archive ouverte pluridisciplinaire HAL, est destinée au dépôt et à la diffusion de documents scientifiques de niveau recherche, publiés ou non, émanant des établissements d'enseignement et de recherche français ou étrangers, des laboratoires publics ou privés. 


\title{
Effet de la nature de l'amidon de l'aliment concentré et de la supplémentation en méthionine sur la production et la composition du lait
}

\author{
S Jurjanz, O Colin-Schoellen, F Laurent
}

INRA-ENSAIA, Laboratoire de Sciences Animales, BP 172, 54505 Vandoeuvre-lès-Nancy Cedex, France

La recherche d'une augmentation du taux protéique du lait a conduit à augmenter la part de concentré dans l'alimentation des vaches laitières. La vitesse de dégradation de l'amidon dans le rumen pouvant avoir des incidences sur la composition du lait (Sauvant et al, 1994, Prod Anim INRA, 7, 115-124), nous avons étudié l'influence d'un apport de blé en comparaison avec un apport de pommes de terre sur la production et la composition du lait.

L'essai a été réalisé avec 12 vaches Prim' Holstein (dont 4 primipares), selon un schéma expérimental en carré latin avec comparaison de 2 natures d'amidon et de 2 niveaux d'apport en méthionine, au cours de 4 périodes de 4 semaines chacune. Les animaux ont reçu des rations complètes isoénergétiques et isoazotées $(0,95 \mathrm{UFL}$ et $107 \mathrm{~g} \mathrm{PDI} / \mathrm{kg} \mathrm{MS})$. Les régimes "blé" ou "pommes de terre" ont été constitués d'ensilage de maïs (respectivement 58 ou $55 \%$ ), de paille $(5,5 \%)$, de blé (17 ou $0 \%$ ), de pommes de terre ( 0 ou $20 \%$ ), de soja $(12 \%)$ et d'un mélange soja-colza tannés 50 : $50(5,5 \%)$, supplémentés ou non ( 0 ou $19 \mathrm{~g})$ en méthionine protégée contre les dégradations ruminales. Les mesures de production laitière (à chaque traite), d'ingestion (5 jours par semaine), des taux protéique (TP) et butyreux (TB) et de la nature des matières azotées du lait ( 4 traites consécutives à deux reprises) ont été réalisées au cours des 10 derniers jours de chaque période. Le poids vif des animaux a été déterminé par double pesée au début de chaque période expérimentale.

La matière sèche ingérée et la production de lait brut n'ont été significativement modifiées ni par la nature du complément énergétique ni par la supplémentation en méthionine. Le TB est significativement $(P<0,01)$ plus élevé pour le régime "pommes de terre" sans qu'il y ait interaction avec le niveau d'apport de méthionine. Par suite, la quantité de matière grasse $(P<0,01)$ et la production de lait à $4 \%$ $(P<0,07)$ sont plus élevées pour le régime "pommes de terre". Le TP ne varie pas significativement sous l'effet du complément énergétique, il est toujours plus élevé avec la méthionine $(P<0,01)$. La teneur en azote non protéique (ANP) du lait est plus élevée pour la ration blé $(P<0,01)$. Le GMQ n'est pas affecté par les traitements.

Pour des rations isoénergétiques la chute marquée du TB enregistrée avec l'apport de blé n'est pas retrouvée avec l'apport de pommes de terre. La production laitière et le TP ne sont pas significativement affectés par la nature de l'amidon. Le TP étant significativement augmenté avec l'apport de méthionine, il est probable que les rations étaient limitantes en cet acide aminé. La nature de l'amidon du concentré influe sur la composition du lait lorsque ce concentré est apporté dans une ration comportant une proportion importante d'ensilage de maïs.

\begin{tabular}{|c|c|c|c|c|}
\hline & PDT - 0 & PDT - MET & BLE - 0 & BLE - MET \\
\hline production (kg/jour) & 26,6 & 26,9 & 27,2 & 27,4 \\
\hline TB $(\mathrm{g} / \mathrm{kg})$ & $38,0^{\mathrm{b}}$ & $37,9 \mathrm{~b}$ & 34,7 a & $33,7 \mathrm{a}$ \\
\hline$T P(g / k g)$ & $32,0 \mathrm{a}$ & $33,0^{\mathrm{b}}$ & $32,5^{a b}$ & $33,0^{\mathrm{b}}$ \\
\hline ANP $(m g / l)$ & $269^{a}$ & $274^{a}$ & $318^{b}$ & $321^{\mathrm{b}}$ \\
\hline matière grasse ( $\mathrm{g} / \mathrm{jour}$ ) & $1050 \mathrm{~b}$ & $1039 \mathrm{~b}$ & $979 a b$ & $938^{a}$ \\
\hline matière protéique ( $\mathrm{g} / \mathrm{jour}$ ) & $888^{A}$ & $914 \mathrm{AB}$ & $914 \mathrm{AB}$ & $930^{\mathrm{B}}$ \\
\hline
\end{tabular}

